\title{
INOVAÇÕES TECNOLÓGICAS E CONTEXTO ESCOLAR: REFLEXÕES NECESSÁRIAS
}

\author{
Maíra da Cunha DARIDO ${ }^{1}$ \\ José Luís BIZELLI ${ }^{2}$
}

RESUMO: Na sociedade moderna as tecnologias têm ocupado um espaço importante exercendo influências em diferentes esferas. Os jovens já nascem imersos na realidade digital e virtual, o que altera as formas de aprender, bem como, de se relacionar com o mundo. Assim, intensifica-se o debate sobre as potencialidades das TIC em meios educacionais e formativos. Nesse estudo, buscou-se investigar a visão dos professores acerca do uso de inovações tecnológicas no ambiente escolar: os limites e possibilidades para o processo de aprendizagem. A amostra foi delimitada com 150 professores do Ensino Médio da rede estadual de São Paulo, no município de Piracicaba. Em continuidade, foram realizadas entrevistas semi-estruturadas com 8 diretores aprofundando questões levantadas pelos professores no questionário. A pesquisa trouxe à tona aspectos importantes para a discussão e encaminhamento de medidas que busquem auxiliar as políticas públicas de inserção das TIC nas escolas. Os professores elencaram as vantagens e desvantagens do seu uso e seu processo de inserção. Observou-se que, apesar dos esforços para implantação, há problemas com infraestrutura das escolas, formação de professores e condições de trabalho.

PALAVRAS-CHAVE: TIC. Visão dos professores. Políticas públicas.

\section{Introdução}

A sociedade brasileira atravessa acelerado processo de transformação que atinge valores éticos fundamentais da convivência entre os cidadãos, recolocando em foco a importância das políticas estratégicas de estado, particularmente aquelas voltadas para a Educação $^{3}$. Na medida em que a velocidade produzida pelo desenvolvimento tecnológico invade todos os campos do conhecimento humano - exigindo respostas educativas e procurando, a todo custo, imprimir seu ritmo às atividades de ensinoaprendizagem - as escolas e os educadores tratam as inovações ou como vitrine para atrair clientes, ou como inimigos a serem combatidos por aligeirarem a reflexão, a crítica ou a capacidade de autoria sobre o próprio processo de construção do conhecimento de cada educando.

\footnotetext{
${ }^{1}$ Mestre em Educação Escolar. UNESP - Universidade Estadual Paulista. Faculdade de Ciências e Letras. Araraquara - SP - Brasil. 14800-901 - maira_darido@yahoo.com.br

2 UNESP - Universidade Estadual Paulista. Faculdade de Ciências e Letras - Departamento de Antropologia Política e Filosofia. Araraquara - SP - Brasil. 14800-901 - bizelli@ fclar.unesp.br

${ }^{3}$ Embora a cidadania seja um valor essencial, a experiência brasileira pregressa ao regime democrático vigente e a dificuldade em lidar com a diversidade cultural impedem a inclusão do tema enquanto disciplina regular do ensino escolar (BIZELLI, 2013).
} 
Ao lado da crença de que a sociedade tecnológica gera movimentos de oportunidades para o desenvolvimento humano (CASTELLS, 1999; LÉVY, 2004), as Tecnologias de Comunicação e Informação (TIC) - suportadas pelas mais diversas plataformas - refletem o movimento estrutural de um sistema que separa e estratifica o acesso e a apropriação da inovação (BIZELLI, 2013). Levando em consideração que apropriar-se dos benefícios materiais das inovações passa pela Educação, é possível afirmar, por exemplo, que as TIC conduzam a uma fórmula diferente de ensinar e aprender, modificando papéis de atores comprometidos com a construção do conhecimento?

Por um lado, não é possível negar a importância das novas tecnologias para o cotidiano da escola, mas é imprudente considerar que as TIC resolverão os desafios educacionais presentes na sociedade brasileira. Imaginar que inovações tragam necessariamente qualidade para a Educação impede a reflexão sobre estratégias para produzir aprendizagem significativa (AUSUBEL; NOVAK; HANESIAN, 1978; NOVAK; GOWIN, 1999; MOREIRA, 1999).

Por outro lado, no afã de resolver o intrincado jogo do ensino-aprendizagem na sociedade em rede, as políticas governamentais investem no que é mais fácil: a garantia de acesso à rede. Máquinas, equipamentos, conexões, espaços físicos, softwares educativos, cursos de formação dão a sensação de progresso rumo à modernidade desejada. Com todo este investimento, qual é a mudança produzida na sala de aula, na relação educador-educando, para apropriação do conhecimento?

As inquietações esboçadas orientaram a investigação que aqui se relata: trata-se da percepção docente acerca da utilização de inovações no ambiete escolar. Segundo a fala dos professores, quais os limites e possibilidades do uso de TIC na sala de aula?

A pesquisa reúne, organiza e interpreta dados colhidos a partir de amostra delimitada em Piracicaba, município do interior do estado de São Paulo. Foram aplicados 150 questionários a profissionais que lecionam no Ensino Médio da rede estadual paulista. Para aprofundamento dos dados coletados, foram realizadas entrevistas semiestruturadas com parte do grupo de professores e com diretores das escolas. A amostra, portanto, contém 150 professores e 7 diretores, os quais estão distribuídos em 10 escolas indicadas pela Diretoria de Ensino de Piracicaba. 


\section{Falando sobre o uso de inovações na escola}

Quando questionados sobre a importância do uso das tecnologias no processo educativo, $49 \%$ dos professores afirmaram acreditar que o uso de TIC nos espaços escolares é muito importante; $39 \%$ acham importante, $11 \%$ julgam pouco importante e $1 \%$ acreditam ser irrelevante, como pode ser visto no Gráfico 01. A visão positiva agrupada - "muito importante" e "importante" - representa 88\% dos professores entrevistados contra $12 \%$ que classificam o uso como pouco importante ou irrelevante.

\section{Gráfico 01 - Crença no uso de TIC no contexto escolar}

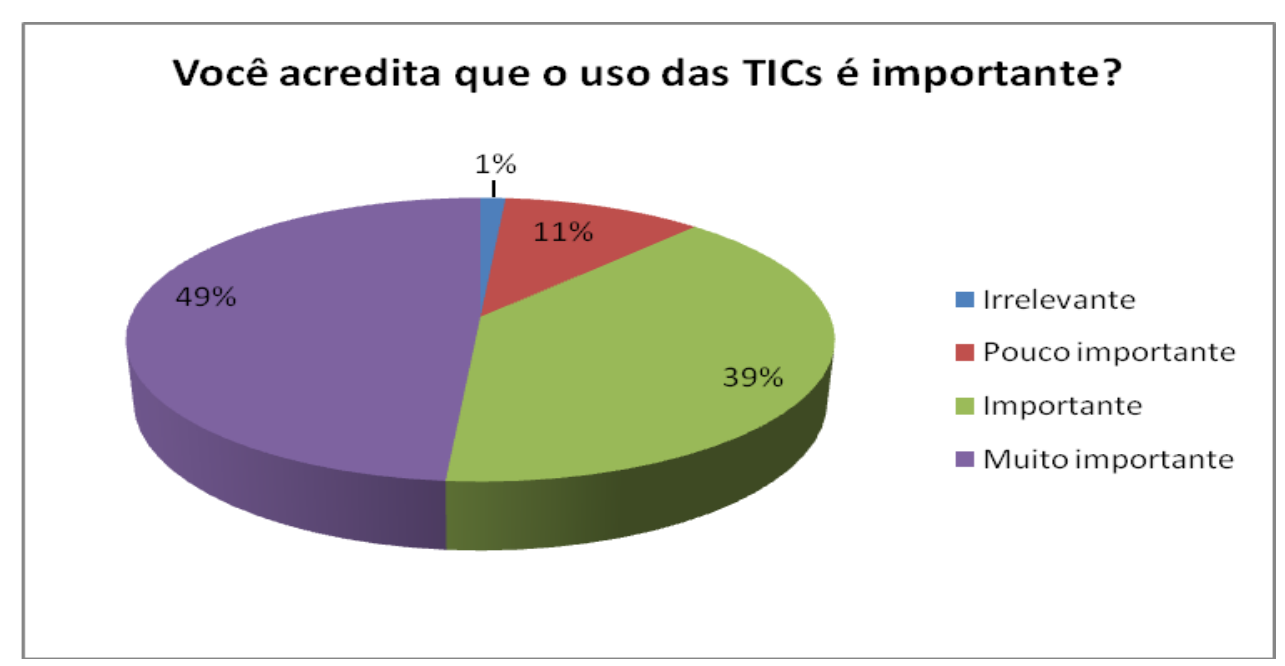

Fonte: Elaboração própria.

É possível entender que a onipresença de TIC em todos os ambientes da vida dos adolescentes cria uma ambiência favorável à incorporação de inovações tecnológicas na escola. Justifica inclusive os esforços feitos pelos gestores da Educação para investir recursos financeiros em vias de acesso público à rede e em educação para o trabalho com professores que não se sentem familiarizados com o computador e a internet. Assim, seria estranho pensar ambientes de aprendizagem sem conexão com a realidade virtual, ou seja, com o mundo digital.

Avaliar, porém, o quanto os educadores reconsideram e refletem sobre suas próprias práticas a partir do uso de TIC como ferramenta de auxílio para ensinar a aprender, ou seja, o quanto eles se apropriam da tecnologia para modificar a forma de fazer Educação, é exercício bem mais difícil. Há uma tendência em abordar a questão de TIC através de velhas fórmulas educativas. 
O perigo do uso irrefletido, embora existente, não invalida o fato de que inovações tecnológicas embora invadam o cotidiano de pessoas de diferentes idades, dominam o universo diário dos nativos digitais (PRENSKY, 2001) cuja intelecção se afasta dos modelos analógicos de representação da realidade, permitindo a construção do pensar digital (BIZELLI, 2013). Os pacotes tecnológicos, cada vez mais, são absorvidos nas tarefas domésticas, na comunicação, no lazer e também na educação (MORAN, 1995).

Tornou-se, portanto, fundamental entender se os professores acreditam que alguma mudança na aula poderia advir do uso de TIC. Subsidiariamente, àqueles que assim considerem, resta saber que tipo de mudança é essa; aos que considerem o contrário resta saber qual a justificativa para sua resposta. Os resultados percentuais podem ser vistos no Gráfico 02.

\section{Gráfico 02 - Você acredita que há alguma mudança na aula com o uso das TIC?}

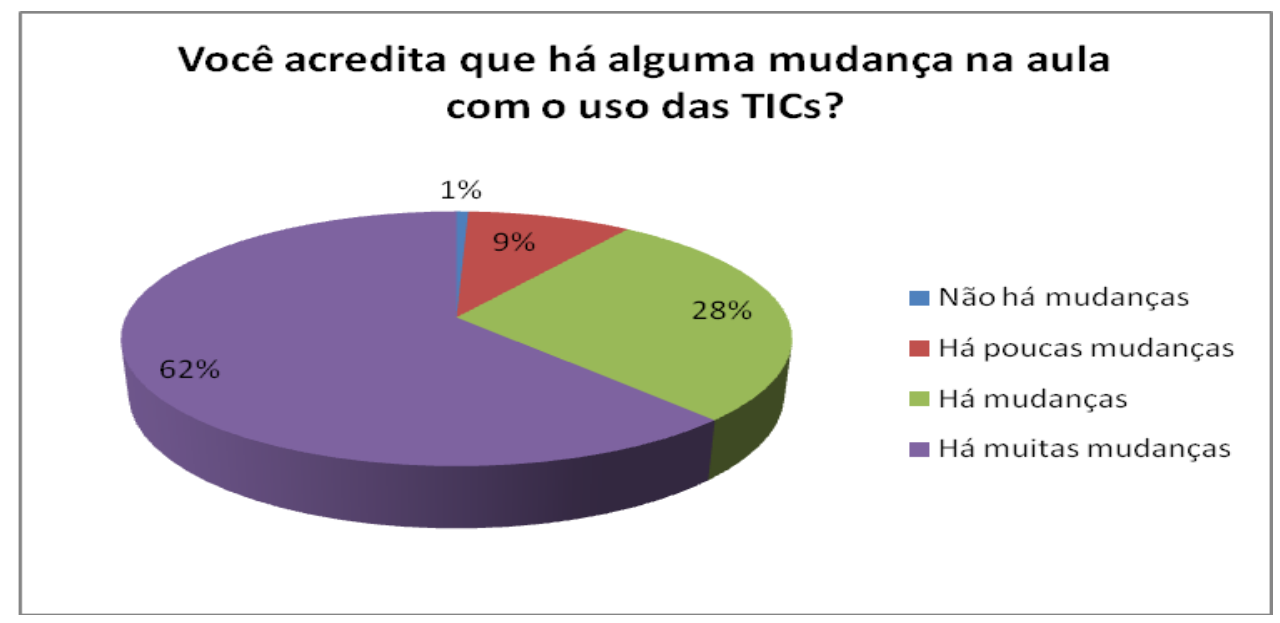

Fonte: Elaboração própria.

Assim, $90 \%$ - 68\% mais 28\% - dos professores acreditam em mudanças provocadas pelo uso de tecnologias na aula contra $10 \%$ - 9\% mais $1 \%$ - que desacreditam. Um dos entrevistados, afirma que "os alunos prestam mais atenção quando eu uso TIC em sala de aula. Sinto a diferença. Mas isso não é determinante, é preciso ter claro qual o objetivo da aula e qual conteúdo se quer passar. TICs ajudam a gente a dar aula, mas não nos substituem nessa empreitada".

Entre os que não acreditam na mudança, há professores que olham para as relações mais estruturais que sustentam a relação do educando com a escola, como pode ser percebido neste trecho de uma entrevista: "Falta motivação, em um primeiro 
momento as tecnologias até prendem a atenção do aluno, depois quando não é mais novidade, os alunos enjoam. Elas (as tecnologias) não fazem mágicas, é preciso entender essa nova geração e qual a relação dela com a escola".

É a prática docente que deve ser repensada. Mesmo que seja possível utilizar meios mais diretos de troca comunicacional entre educadores e educandos é a relação ensino-aprendizagem em sala de aula que cria inovação em todos os campos da educação (MAGALHÃES; MILL, 2013).

Assim, é necessário ter claro o que se quer ensinar, pois a inserção de TIC nas escolas não vem como salvação para um problema que continua presente na prática docente. Só quando as inovações geram transformações na prática docente e na revisão de metodologias do processo de ensino-aprendizagem são capazes de apontar para incremento positivo na capacidade de apropriação de conhecimentos por parte dos educandos.

Educadores têm que ser formados para exercer o papel de condutores em um mundo cujas informações estão disponíveis nas pontas dos dedos; um mundo onde quanto mais simples é o acesso, mais complexo é a sua sistematização e entendimento para o exercício da liberdade de escolha.

\section{Formação inicial e continuada: metodologia e ações pedagógicas}

Ao serem indagados sobre o quanto se sentiam preparados no uso das TIC em sala de aula, apenas $15 \%$ da amostra se sentem aptos para o exercício proposto. A maioria absoluta (79\%) afirma não estar preparada e 6\% se consideram parcialmente preparados.

\section{Gráfico 03 - Se sentem preparados para o uso de TIC em sala de aula?}

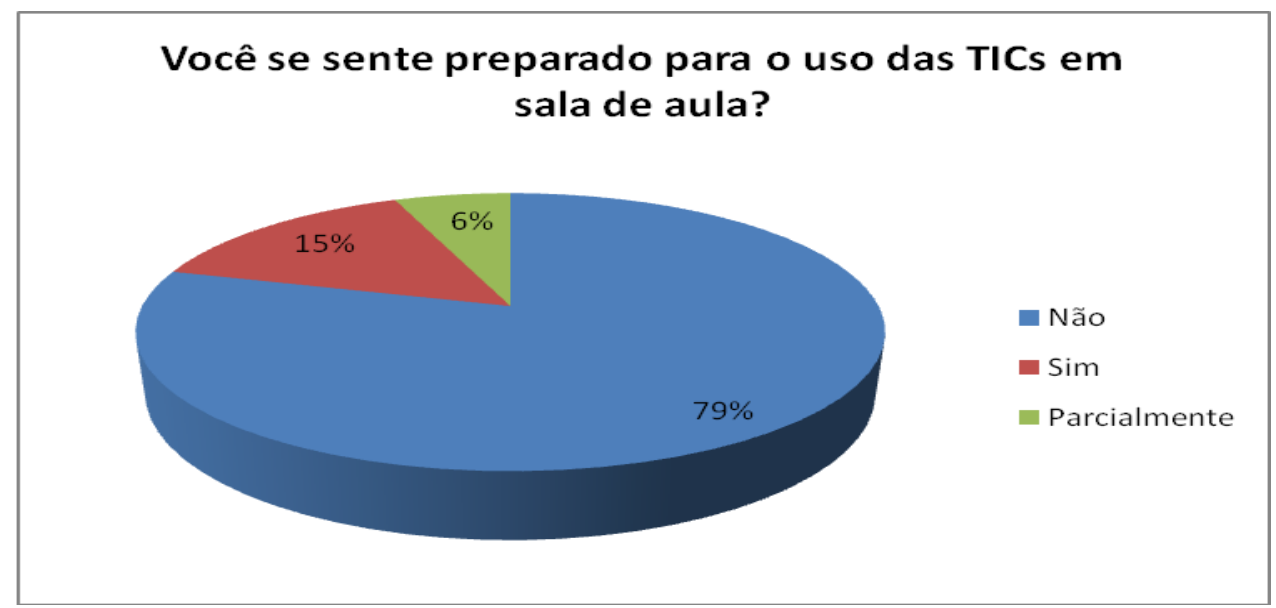

Fonte: Elaboração própria. 
Embora acreditem na importância do uso de inovações, apenas $15 \%$ se sentem seguros para usá-las. Muitos são os impactos efetivos dos meios digitais para o ambiente escolar: novos modelos de aulas; um estilo próprio de planejamento em tempo real; incrementos de disciplinas nos currículos que atendam habilidades novas; outra forma de se comunicar e organizar recursos.

Extrapola-se a questão de infraestrutura e se caminha para a reflexão sobre o choque cultural promovido pela convivência e pelas mudanças de comportamento entre diferentes gerações (PRENSKY, 2001). Educadores que - conforme foi visto - têm pouca inserção de TIC em sua vida cotidiana, ou não têm destreza para utilizá-las, são chamados a liderar processos inovativos em Educação.

Ao olhar a questão da familiaridade com as tecnologias sob a ótica da faixa etária do respondente, é mais fácil entender a diferença que faz o aspecto geracional: 100\% dos professores com até 30 anos se sentem preparados para o uso de TIC em sala de aula, enquanto $90 \%$ dos que têm acima de 50 anos se julgam despreparados, como exemplifica a fala:

\begin{abstract}
A gente nunca precisou disso (TIC) para aprender. Eu acredito que seja importante, mas é uma questão de geração; fui aprender a ligar um computador com mais de 40 anos. Hoje em dia, parece que as crianças já nascem sabendo. A minha geração demorou a fazer uso das tecnologias. Eu vou tentando, mas reconheço minhas limitações até mesmo para digitar uma prova.
\end{abstract}

A velocidade que adquirem as mudanças em tempos de Modernidade Líquida (BAUMAN, 2001) passa a exigir a reconstrução dos elementos cotidianos gerando insegurança no trabalhar com o constantemente novo. O professor é peça chave para o desdobramento das TIC em processo de ensino e aprendizagem mais eficaz. Muitos docentes são "imigrantes digitais" com o compromisso de ensinar "nativos digitais", que aprendem em ritmos e de maneiras diferentes: há choque cultural de gerações na relação professor e estudante, apresentando novas facetas de um mesmo conflito.

Vários autores (MORAN, 1995; BELLONI, 2005; BIANCHI; PIRES; VANZIN, 2008; KENSKI, 2007; SILVA, 2011; CRUZ; BIZELLI, 2014) consideram que educadores precisam educar-se para utilizar inovações tecnológicas, desenvolvendo e aperfeiçoando metodologias que promovam aprendizagem. Isso deve ser acompanhado de condições adequadas de formação continuada, estruturas, recursos, tempo e remuneração. 
A formação continuada para o uso de TIC deve ser algo sistemático ao longo da carreira de educadores, já que as novas plataformas têm como característica o constante processo de aperfeiçoamento. Aquilo que foi aprendido há dois anos já está, hoje, defasado, uma vez que os suportes, os programas e os softwares recebem atualizações periódicas, modificando atalhos básicos para uso.

Entre os entrevistados, surgem diferentes discursos para justificar o sentimento de preparo ou despreparo para utilização de TIC, como se pode ver no Quadro 01.

Quadro 01 - Justificativas dos entrevistados sobre seu preparo no uso de TIC.

\begin{tabular}{|c|c|}
\hline Sujeito 1 & Se sente preparado, porque tecnologias fazem parte do dia-a-dia, mesmo fora da escola. \\
\hline Sujeito 2 & Em parte, acredita que poderia ter mais formação para o uso de TIC. \\
\hline Sujeito 3 & $\begin{array}{l}\text { Não se sente preparado, pois sofre para sistematizar suas aulas em TIC e gostaria de ter } \\
\text { ajuda para fazer isso. }\end{array}$ \\
\hline Sujeito 4 & Não se sente preparado; acredita não ter formação para utilizá-las. \\
\hline Sujeito 5 & $\begin{array}{l}\text { Não se sente preparado, pois não sabe ligar o equipamento e não acha necessário para a } \\
\text { relação de ensino-aprendizagem. }\end{array}$ \\
\hline Sujeito 6 & $\begin{array}{l}\text { Se sente preparado, mas acredita que deveria haver um técnico especializado para } \\
\text { auxiliar os professores nas aulas. }\end{array}$ \\
\hline Sujeito 7 & $\begin{array}{l}\text { Se sente preparado em partes. Acredita não ter formação para utilizá-las adequadamente. } \\
\text { Acredita que há a necessidade de mais apoio e monitoria para desenvolver o trabalho. }\end{array}$ \\
\hline Sujeito 8 & Não se sente preparado. Já tentou usar, mas alega não ter tempo para preparar as aulas. \\
\hline Sujeito 9 & $\begin{array}{l}\text { Sim, se sente preparada, mas acredita que poderia haver um suporte melhor e mais } \\
\text { vontade da equipe gestora em facilitar o uso do material. }\end{array}$ \\
\hline Sujeito 10 & Sim, acha que é fundamental, e não imagina mais a escola sem esses recursos. \\
\hline
\end{tabular}

Fonte: Elaboração própria.

Assim, podem ser elencados fatores que corroboram o despreparo dos professores para o uso de TIC: falta formação inicial ou continuada efetiva para uso de ferramentas eletrônicas ou digitais; necessidade de mais apoio técnico para uso dos equipamentos, inclusive pessoas de suporte e apoio de gestores. 
Sobre a formação de professores, Bianchi, Pires e Vanzin (2008) acredita que o uso do aparelho tecnológico por si só não ensina nada, sendo preciso que o professor elabore novas metodologias e estratégias de ensino. A formação do educador, portanto, é fator crítico para a incorporação efetiva de TIC no ambiente escolar. Segundo Valente (2010), essa formação deve prepará-lo para construir conhecimento, identificar potencialidades dos educandos, dominar sua área de conhecimento e incluir tecnologias nos processos.

As pressões sobre os profissionais da área da educação vêm da necessidade de cada vez mais responderem às demandas dos programas do governo e às demandas dos educandos, os quais aparecem diariamente com inovações que desmotivam a participação no modelo de aula vigente. O mais simples trabalho exige certo trânsito ou familiaridade com TIC. A saída, segundo Belloni (2005), é a utilização sem muita reflexão, o que se transforma em válvula de escape:

Eu fiz curso de capacitação oferecido pelo governo, aprendi a mexer em algumas coisas. Quando fui usar na minha escola, a versão do computador era outra, os cabos eram diferentes. Tenho muita dificuldade porque cada hora chega uma coisa nova, de um jeito diferente. Para a gente que tem mais idade, isso é complicado, mal aprendemos uma coisa e já tem outra nova.

As tecnologias não mudam apenas as estratégias de ensino, mas toda a concepção e percepção de educadores, de educandos, da escola, da educação. Ou seja, mudam a maneira de ensinar e a forma de aprender: o "como" os estudantes recebem, constroem e se relacionam com o conhecimento (SANCHO, 2006).

Para Lévy (1999), diante da velocidade com que as técnicas parecem surgir diante da multiplicidade de atores e interesses envolvidos no processo - as formas de uso vão se impondo enquanto se discutem novas possibilidades. A velocidade do mundo digital é um dos motivos para a estranheza e para a sensação de deslocamento com o uso de inovações tecnológicas. Enquanto se avalia adequadamente o melhor uso de uma ferramenta, uma nova técnica já está sendo apresentada.

A fragmentação do processo e a pulverização dos atores não permitem um domínio sobre todo o processo: “[...] a aceleração é tão forte e tão generalizada que até mesmo os mais 'ligados' encontram-se em graus diversos, ultrapassados pela mudança. O sentimento de estranheza cresce com a separação das atividades e a capacidade dos processos sociais." (LÉVY, 2007, p. 28). 
Assim, aponta-se para um aprofundamento das reflexões sobre o papel de TIC no contexto educacional: quais são, pedagogicamente falando, as possibilidades e limites do uso de inovações. Como expresso por Bianchi, Pires e Vanzin (2008, p. 55),

[...] por mais potentes que sejam os computadores ou por mais velozes que sejam as redes de transmissão, não irão acabar com todos os problemas que envolvem a questão da inserção de tecnologias na educação, pois as tecnologias têm implicações políticas, econômicas, sociais e culturais que precisam se observadas com a maior atenção quando introduzidas em espaços educativos.

As escolas públicas e as comunidades carentes precisam ter acesso garantido para não ficarem condenados à segregação definitiva, ao analfabetismo tecnológico e ao ensino de quinta classe (MORAN, 1995).

É tarefa que desafia o cotidiano do educador diminuir a segregação tecnológica, tarefa para a qual ele precisa de suporte a fim de que possa concentrar-se na utilização pedagógica da Internet e dos programas multimídias.

Os cuidados para não se perder ou não se prender às inovações dependem de um sólido conhecimento e de uma intuição apurada para o desenvolvimento ético e objetivo da apropriação dos conteúdos que circulam na rede e seus efeitos sobre a aprendizagem dos educandos.

\section{Infraestrutura e condições de trabalho docente}

A crise na educação é um reflexo da crise da sociedade moderna (ARENDT, 2005). Assim, para compreender os problemas na escola, é preciso analisar a sociedade em que ela está inserida.

A crise na educação para Arendt (2005) não é má em si mesma, já que permite um repensar práticas cotidianas inerentes à sociedade moderna. A dicotomia se centra na questão da novidade e da conservação, que se coloca historicamente para a existência humana.

Reflexo dessa dicotomia pode ser observado quando os professores são questionados sobre se usam TIC em sala. Dos professores entrevistados, $45 \%$ usam quando possível; $23 \%$ usam raramente; $17 \%$ usam muito; $8 \%$, nunca usam e $7 \%$ dizem não usar por não ter acesso à rede na escola. 


\section{Gráfico 04 - O uso de TIC em sala de aula}

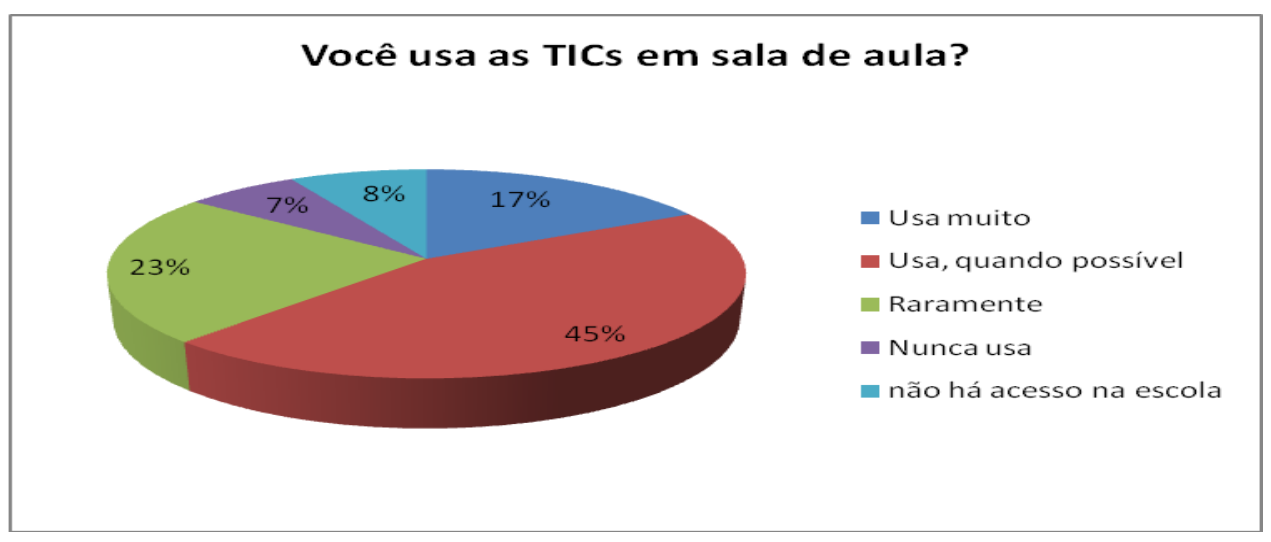

Fonte: Elaboração própria.

Enquanto $88 \%$ dos professores acham importante o uso de inovações tecnológicas em sala de aula, $62 \%$ usam muito ou quando possível. Retrata-se a escola de Piracicaba, onde apesar dos investimentos em infraestrutura, não há porcentagem efetiva de professores que afirmam utilizar TIC.

Há dificuldades na baixa quantidade e diversidade de materiais que a escola oferece e há dificuldades para vencer os procedimentos para manutenção e instalação dos equipamentos (CHAMPANGNATTE; NUNES, 2011). Perduram questões estruturais: requisitos básicos para que o trabalho com as tecnologias seja realizado de modo adequado, apesar do investimento oriundo de programas governamentais.

O tempo do professor também está comprometido: "Eu poderia me esforçar mais para aprender a usar, mas dou 50 aulas semanais, não tenho tempo de organizar minhas cadernetas, muito menos pensar numa aula em que eu possa inserir as TIC'.

As condições de trabalho refletem na qualidade de ensino ofertado. Devido aos baixos salários, educadores sentem necessidade de acumular funções, jornadas de trabalho ou mais de um emprego. No questionário, 69\% dos professores apontaram acúmulo de função, ou seja, dão aula como efetivos em uma escola e possuem outros empregos ou dão aula em escolas particulares. Evidencia-se a necessidade de melhores salários, melhores condições de trabalho e valorização social da função docente.

A forma de organizar atividades, a falta de preparo e a falta de infraestrutura da escola foram motivos apontados nas entrevistas dos educadores para a não utilização de inovações em sala de aula. Já diretores apresentaram diferentes hipóteses para o baixo uso de TIC na escola e confirmaram a baixa adesão dos professores quanto ao seu uso ${ }^{4}$.

\footnotetext{
${ }^{4}$ A voz discordante foi uma Diretora da única Escola em Tempo Integral.
} 
Três hipóteses são levantadas pelos diretores: a resistência do professor em utilizar inovações na educação; a insegurança do professor frente ao seu pouco preparo e formação em ferramentas tecnológicas ${ }^{5}$; e a falta de tempo para estudo e preparo das aulas incrementadas por TIC.

Duas questões se colocam. Primeira, o que pode impulsionar uma mudança significativa de atitude? Bauman (2001) afirma que a marca da modernidade é a "vontade de liberdade", único sentimento capaz de acompanhar a velocidade das mudanças econômicas, tecnológicas, culturais e do cotidiano. Não há como se sentir seguro e estável, pois é tudo muito incerto e assustador. Não há utilidade para a "certeza", para a "segurança", ou mesmo para a "estabilidade”. Aquele desejo imenso de poder que animou a busca do definitivo desperta, agora, pouco entusiasmo. A paixão repousa na representação do papel de consumidor.

Segunda questão, que relações de poder são essas que sobrevivem às inovações? As tecnologias requentam os confrontos internos: professores versus professores; educadores versus educandos; professores versus coordenadores. A introdução da inovação não encontra espaço aberto para produzir novidade, criação e reflexão. Reproduzem-se as estruturas hierárquicas internas.

Compreender as estruturas de poder em sociedade é condição para entender a dimensão da reprodução social (BOURDIEU, 1996) que existe no espaço escolar. É difícil pensar nos múltiplos problemas sociais, sem entender o seu reflexo na escola.

Assim, poder e educação se aproximam: os moldes escolares têm bases firmadas em modelos disciplinares. Ao invés de considerar que existe a construção do saber somente na ausência dos poderes coercitivos, Foucault (1979) faz o caminho reverso e considera que é justamente o poder que produz o saber. Não há saber que não construa relações de poder e nem poder que não pressuponha um campo de saber.

Baseado no disciplinamento, na vigilância, no controle, nas provas e exames, é possível construir um retrato das práticas e estruturas escolares. Desde a disposição das carteiras, a construção dos corredores até a postura dos professores em sala de aula e a construção do currículo escolar refletem hierarquias e relações de poder que impõem a uma multiplicidade de indivíduos condutas unificadas. Sujeitos disciplinados, obedientes, respondem às necessidades das instituições geradas pela sociedade

${ }^{5}$ Principalmente frente ao domínio que os jovens têm sobre a tecnologia, o que os levaria a romper com a visão tradicional de educação, onde o professor seria o detentor do conhecimento e teria como função depositar no "aluno" todo seu conhecimento - a chamada educação bancária (FREIRE, 1979). 
moderna. A forma como a escola se apresenta é a que melhor cumpre seu papel para a construção do projeto de modernidade existente.

É interessante perceber que o ritmo da incorporação de novas tecnologias ao cotidiano escolar é lento. Mesmo os que enfrentam as dificuldades materiais e as relações de poder estabelecidas levam as formas mais tradicionais de tecnologias para dentro da sala de aula. Uma das questões respondidas perguntava sobre o tipo de ferramenta usado. A pergunta foi direcionada aos que declararam incorporar TIC em sala de aula e permitia que se elencasse mais de uma resposta.

Em 234 ocorrências: 112 respostas corresponderam à utilização de transmissão de vídeos; 72 respostas apontaram para a transmissão de slides e apresentações dos conteúdos sistematizados em aula; 43 respostas indicaram uso dirigido à apresentação de trabalho de educandos, 5 respostas mencionaram outros fins e apenas 2 respostas apresentaram como possibilidade a realização de trabalhos em rede. As frequências ficam mais claras a partir do Quadro 02, disponível na sequência do texto.

Quadro 02 - De que forma as TIC são utilizas nas escolas

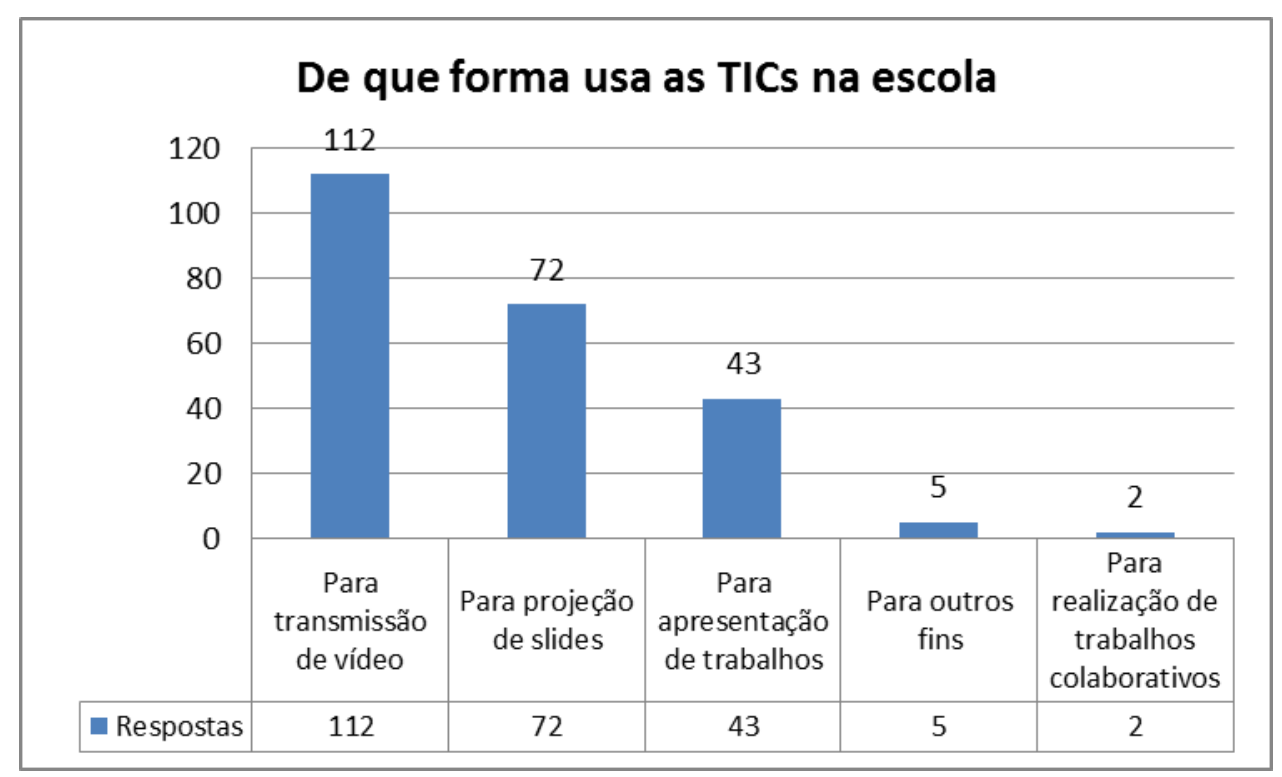

Fonte: Elaboração própria.

O movimento de transmissão de vídeo na escola começa na década de 1960 e não é tratada como prática reflexiva. Segundo Tardy (1976), não há uma discussão reflexiva a respeito da gradativa assimilação das imagens cinematográficas, nem clareza para o uso dos vídeos na escola. Valente (2010), por sua vez, defende que é o computador que deve estar presente no cotidiano escolar, já que ocupa lugar de destaque 
na vida dos jovens. Para que isso aconteça, há que se quebrar o paradigma educacional, promovendo aprendizagem ao invés de ensino, saindo da pedagogia instrucionista para a construcionista: o educando tem que construir seu conhecimento através da tecnologia.

A educação aliada às inovações tem que permear todo o currículo escolar para não se tornar apenas apêndice das aulas ou marketing da escola. A chave é o letramento digital de todos os envolvidos, de forma que não sejam meros apertadores de botões (alfabetizados digitais), mas sejam capazes de usar a tecnologia em práticas sociais (VALENTE, 2010).

Segundo Lévy (2004), é importante entender as mídias como meio de transmitir o conhecimento, já que quem direciona o conteúdo é o professor. No entanto, não se trata de fazer "mais do mesmo", já que para isso não é preciso usar o aparato tecnológico. O que se quer é encontrar caminhos que possibilitem a produção do conhecimento através da ótica digital.

Há nos tempos atuais uma supervalorização do poder do audiovisual, que pode ser utilizado de três maneiras distintas nas escolas: 1) como forma instrumental de sistematizar as disciplinas em sala de aula, ou seja, como forma ilustrativa; 2) como forma de conhecer a gramática audiovisual, através das linguagens e usufruto dos códigos digitais, voltada à lógica de preparação do estudante para o mercado de trabalho; ou 3) como forma de produção do conhecimento, explorando facilidades e possibilidades de edição e de criação no processo de ensino-aprendizagem.

O grande desafio, porém, é delinear estratégias e formas de apropriação de TIC para a produção do conhecimento. É preciso repensar a prática docente como mediação de novos conhecimentos, direcionando caminhos rumo à aprendizagem significativa e auxiliando no alcance dos objetivos e expectativas de aprendizagem.

\section{Algumas considerações}

A modernidade imprime velocidade vertiginosa nos processos de mudança atingindo as organizações escolares. Segundo Giddens (1991, p. 13): "as consequências da modernidade estão se tornando mais radicalizadas e universalizadas". Um fator que potencializa a velocidade das mudanças é a tecnologia.

Shwartzman (1991) afirma que a tecnologia deve ser entendida como filha bastarda da modernidade, já que protagoniza a modernização da sociedade, mas não vem acompanhada de reflexão sobre sua inserção. 
Embora atores desavisados tenham sugerido que com as inovações tecnológicas o educador pudesse perder seu papel fundamental na construção do conhecimento, hoje se percebe que sem ele não há "modernização" na escola. O professor é o protagonista da mediação entre disponibilidade de informação e conhecimento (LÉVY, 2004; BELLONI, 2005; ARROYO, 2006; KENSKI, 2007).

Ganha importância, portanto, compreender o processo de inserção de TIC em sala de aula, a partir da voz dos educadores, facilitando um processo de formulação de políticas públicas mais ajustado às práticas docentes. É a partir do professor que se deve desencadear a transformação para uma educação de melhor qualidade. Melhorar as condições de tabalho do professor é melhorar as condições de educação no país (SILVA, 2011).

A valorização da profissão docente deve ser, por um lado, compromisso político que possibilite melhorar as condições de trabalho, equiparando o salário às categorias de nível superior, possibilitando uma única jornada ao professor. Por outro lado, deve haver formação continuada para sanar a lacuna geracional que se estabelece entre educadores e educandos. Ao mesmo tempo, a infraestrutura e a condição de trabalho aparecem como fatores essenciais a $79 \%$ de professores entrevistados que não se consideram preparados para usar TIC em sala de aula, apesar de que 90\% acreditam haver mudanças no processo de ensino/aprendizagem através das inovações tecnológicas. Entrevistas e questionários apontaram como fator impeditivo para o uso de TIC nas escolas a dificuldade de instalação e manutenção de equipamentos, dificuldade que se atrela à gestão e ao controle exercido pela Secretaria de Educação do Estado de São Paulo.

Gastos com tecnologia devem refletir melhoria na infraestrutura das escolas que não podem ser prejudicados por má gestão financeira ou falta de planejamento coletivo. Educadores e funcionários têm que estar aptos para o uso dos equipamentos de forma crítica e construtiva. Sem estes fatores, não há tecnologia que dê conta de ensinar.

Para Ioschpe (2012), os erros da educação não podem ser solucionados apenas com tecnologia, uma vez que ensinar o mesmo conteúdo do livro na lousa digital não faz sentido, não promove mudanças. Conclui-se, portanto, que as mudanças estão na busca por outras formas de ensinar com inovações, o que passa por melhor gestão política e de investimentos para transformar TIC em recurso pedagógico de aprendizagem. 
Pela fala dos educadores e pelas análises das faixas etárias, observa-se a existência de uma transição geracional. Muitos profissionais da Rede Estadual são "nativos digitais", mas para a grande maioria tudo é novo. O desconhecimento gera medo e insegurança. O quadro que as tecnologias ajudam a pintar tem raízes mais profundas na crise da prática docente. Os protagonistas das mudanças são os jovens que advogam a necessidade de romper com os modelos conservadores de educação, baseados no professor que ensina conteúdos e no "aluno" desprovido de saberes.

O desafio está claro: educação criativa, reflexiva e crítica através de educadores e educandos que tenham acesso aos meios digitais, apropriem-se dessas ferramentas para reestruturarem suas práticas e reinventem a escola enquanto espaço educativo significativo.

\title{
TECHNOLOGICAL INNOVATIONS AND SCHOOL CONTEXT: REFLECTIONS REQUIRED
}

\begin{abstract}
In modern society technologies have played an important space exerting influences in different spheres. Today's young people are born immersed in the digital and virtual reality, which has changed the ways of learning, as well as to relate to the world. All this context has intensified the debate on the potential of ICT in education and training means. In this study, we sought to investigate the teachers' vision of ICT in the school environment, how they are being incorporated into the school and the limits and possibilities of the use of ICT in the learning process. Questionnaires were administered to 150 teachers who teach in high school in the state network of São Paulo teaching, but specifically in Piracicaba. Continuing, semi-structured interviews with a group of 8 directors were carried out so that there was a deepening on the issues raised by teachers in the questionnaire. The research brought to light important issues for discussion and referral measures striving to support public policies of integration of ICT in schools. Teachers spoke about the advantages and disadvantages of their use and the process of integration. It was observed that, despite efforts to implementation, there are still problems with infrastructure of schools, teacher training and working conditions.
\end{abstract}

KEYWORDS: ICT. Teachers view. Public policy.

\section{REFERÊNCIAS}

ARENDT, H. A crise na educação. In: Entre o passado e o futuro. Tradução de Mauro W. Barbosa de Almeida. 5.ed. São Paulo: Perspectiva, 2005. p.162-204. 
ARROYO, M. G. Los movimientos sociales y la construcción del derecho a la educación. In: SACRISTAN, J. G. (Org.). La reforma necesaria: entre la política educativa y la practica escolar. Madrid: Morata, 2006. p.123-143.

AUSUBEL, D. P.; NOVAK, J. D.; HANESIAN, H. Educational psychology: a cognitive view. 2.ed. New York: Holt, Rinehart e Winston, 1978.

BAUMAN, Z. Modernidade líquida. Tradução de Plínio Dentzien. Rio de Janeiro: Jorge Zahar, 2001.

BELLONI, M. L. O que é mídia-educação. 2.ed. Campinas, SP: Autores Associados, 2005.

BIANCHI, P; PIRES, G. L.; VANZIN, T. As tecnologias de informação e comunicação na rede municipal de ensino de Florianópolis: possibilidades para a educação (física).

Revista Linhas, [S.1.], v.9, n.2, p.56-75, jul./dez. 2008.

BIZELLI, J. L. Inovação: limites e possibilidades para aprender na era do conhecimento. São Paulo: Ed. da UNESP ; Cultura Acadêmica, 2013. v.1.

BOURDIEU, P. Razões práticas: sobre a teoria da ação. Tradução de Mariza Corrêa. Campinas: Papirus, 1996.

CASTELLS, M. A sociedade em rede. São Paulo: Paz e Terra, 1999.

CHAMPANGNATTE, D. M. O.; NUNES, L. C. A inserção das mídias audiovisuais no contexto escolar. Educação em Revista, Belo Horizonte, v.27, n.3, p.15-38. 2011.

CRUZ, J. A. S.; BIZELLI, J. L. Ensino superior e a formação de docentes: educar para os meios a partir da pós-graduação lato sensu. In: CONGRESSO BRASILEIRO DE CIÊNCIAS DA COMUNICAÇÃO, 37., 2014, Foz do Iguaçu. Anais... Foz do Iguaçu: Intercom, 2014. p.01-14. Disponível em:

<http://www.intercom.org.br/papers/nacionais/2014/resumos/R9-0111-1.pdf>. Acesso em: 29 mar. 2015.

FOUCAULT, M. Microfísica do poder. Rio de Janeiro: Graal, 1979.

FREIRE, P. Educação e mudança. 14. ed. Rio de Janeiro: Paz e Terra, 1979.

GIDDENS, A. As consequências da modernidade. São Paulo: Ed. da UNESP, 1991.

IOSCHPE, G. A tecnologia não nos salvará (por enquanto). Veja, São Paulo, 18 mar. 2012. Disponível em: <http://veja.abril.com.br/noticia/educacao/a-tecnologia-nao-nossalvara-por-enquanto>. Acesso em: 06 jan. 2013.

KENSKI, V. M. Educação e tecnologias: o novo ritmo da informação. Campinas, SP: Papiros, 2007.

LEVY, P. A inteligência coletiva. São Paulo: Loyola, 2007. 
LEVY, P. A conexão planetária: o mercado, o ciberespaço, a consciência. São Paulo: 34, 2004.

LEVY, P. Cibercultura. São Paulo: 34, 1999.

MAGALHÃES, C. M.; MILL. D. Elementos para reflexões sobre educação, comunicação e tecnologia: nada é tão novo sobre redes, linguagens e aprendizagem. Revista Educação Temática Digital, Campinas, v.15, n.2, p.320-336, 2013.

MORAN, J. M. Novas tecnologias e o re-encantamento do mundo. Tecnologia educacional, Rio de Janeiro, v.23, n.126, p.24-26, set./out. 1995.

MOREIRA, M. A. Aprendizagem significativa. Brasília: Ed. da UnB, 1999.

NOVAK, J. D.; GOWIN, D. B. Aprender a aprender. 2.ed. Lisboa: Plátano, 1999.

PRENSKY, M. Digital natives, digital immigrants. On the Horizon, [S.1.], v.9, n.5, p.01-06, oct. 2001. Disponível em:

<http://www.marcprensky.com/writing/Prensky\%20-

\%20Digital\%20Natives, \%20Digital\%20Immigrants\%20-\%20Part1.pdf > . Acesso em: 13 mar. 2008.

SANCHO, J. M. De tecnologias da informação e comunicação a recursos educativos. In: SANCHO, J. M.; HERNÁNDEZ, F. et al. Tecnologias para transformar a educação. Tradução de V. Campos. Porto Alegre: Artmed, 2006. p.15-41.

SHWARTZMAN, S. Educação básica no Brasil: a agenda da modernidade. Revista Estudos Avançados, São Paulo, v.5, n.13, p.49-60, 1991.

SILVA, A. C. Educação e tecnologia: entre o discurso e a prática. Ensaio: Avaliação e Políticas Públicas em Educação, Rio de Janeiro, v.19, n.72, p.527-554, jul./set. 2011.

TARDY, M. O professor e as imagens. São Paulo: Cultrix, 1976.

VALENTE, J. A. As tecnologias e a verdadeira inovação. Pátio: Ensino Fundamental, Porto Alegre, v. 14, p. 6-9, 2010. Disponível em: <www.grupoa.com.br/revistapatio/artigo/6315/as-tecnologias-e-a-verdadeira-inovacao.aspx>. Acesso em: 14 mar 2013. 